Strogilos, V., Tragoulia, E., Avramidis, E., Voulagka, A., \& Papanikolaou, V. (2017). Understanding the development of differentiated instruction for students with and without disabilities in co-taught classrooms, Disability \& Society. https://doi.org/10.1080/09687599.2017.1352488. IF: 1.145

\title{
Understanding the Development of Differentiated Instruction for Students With and Without Disabilities in Co-Taught Classrooms
}

\begin{abstract}
Differentiation has gained international attention as a strategy associated with responsive teaching, and as a means for ensuring access to the curriculum for all pupils. This study investigates the development of differentiated instruction in thirty four Greek co-taught classrooms. The aim is to explore how co-teachers understand the term 'differentiated instruction', and to identify the conditions surrounding its implementation as an inclusive strategy. Sixty eight semi-structured interviews and fifty seven unstructured narrative observations were implemented with mainstream and special education co-teachers. We suggest that co-teachers understood differentiated instruction as a 'child's deficit oriented activity' for students with disabilities and not as a 'context oriented approach' for all students. Co-teachers attributed the limited differentiated instruction observed to several contextual factors. However, we argue that the understanding of disability through the medical model and Foucault's 'medical gaze' results in the construction of differentiated instruction as a remedial approach and, by extension, its limited use in mainstream classrooms.
\end{abstract}

\section{Points of Interest}

- This article focuses on differentiated instruction as a means to inclusion for all students.

- The current study aims to explore how 34 pairs of general and special education teachers understand the term 'differentiated instruction', and which factors they perceived as crucial in determining the way differentiation is implemented in co-taught classrooms.

- The co-teachers indicated that factors such as lack of training, lack of collaboration, the large number of students per class, and their strict commitment to cover the curriculum hinder the development of differentiated instruction.

- The teachers considered differentiated instruction as an approach to 'fix' the deficits of the children with disabilities and not as an approach to improve the curriculum for all students.

- Co-teachers need to learn to become flexible, to permit the shift of meaning in situations taken for granted (e.g. students with disabilities learn better through individual teaching) and hence to deconstruct established beliefs. 
The legislative and policy trends of the past thirty years have revealed a shift towards less segregated practices in the education of all students, including those with disabilities. The development of inclusive schools where learning and participation is ensured for all students seems to be an important goal around the world. World Declarations and Statements and UN Conventions have forced governments to restructure their educational policies to develop inclusive practices in mainstream schools so as to increase participation and improve the quality of education offered to all students (e.g. The United Nations Convention on the Rights of Persons with Disabilities and its Optional Protocol 2007).

Several authors have urged for the development of educational practices that promote meaningful access to learning and eliminate exclusion. For example, Slee $(2013,2)$ cogently argues that in spite of "financial expenditure and optimistic talk exclusion remains a real and present danger". He notes that the current policies on inclusion involve the operation of traditional mechanisms to identify children with special educational needs (SEN), and concludes that this process creates more strangers, more 'surplus' children and thus more exclusion. With regard to students with disabilities, evidence exists that their placement at mainstream schools has often not been followed by meaningful access to learning (Nind and Wearmouth 2006; Scruggs, Mastropieri, and McDuffie 2007) and many concerns have been expressed about the support offered to these students in many countries (Rix et al 2013; Smyth et al 2014). Thus, this study aims to discuss practices that provide meaningful access to learning such as differentiated instruction (DI) in co-taught classrooms. In particular, we consider DI as one of the essential means to effective education for all students including those with disabilities That is because, as Tomlinson argues (2005), differentiation is associated with responsive teaching and not "one size fits all" teaching. Thus, when teachers differentiate they 'proactively plan varied approaches to what students need to learn, how they will learn it, and/or how they will show what they have learned in order to increase the likelihood that each student will learn as much as he or she can, as effectively as possible' (Tomlinson 2003, 151).

The analysis of the current Greek legislation (3699/2008) and practice indicates that the Greek education system is highly centralised (Strogilos 2012), and has a long tradition in undifferentiated learning. The last fifteen years and after the integration of a large number of students with diverse learning needs (e.g., students with a minority background or disabilities) in mainstream classrooms, the issue of differentiated instruction appeared in the public discourse. Several training conferences on differentiation have been organized by Universities, new undergraduate and postgraduate modules are now included in many University programmes, and publications on this issue are now evident in Greek academic journals and books (e.g. Pandeliadou and Argyropoulos 2011). In addition, the term 'differentiation' has started appearing in some policy documents. For example, in the Law 4115/2013 it is stated that the 'district's multidisciplinary team' (i.e. the team of professionals who implement the diagnosis and support of students with disabilities) should design a differentiated curriculum for students with special needs or behaviour problems in collaboration with the class teacher. Recently the term 'differentiation' was introduced in the new pilot National Curriculum (Pedagogical Institute, 2011) for mainstream schools; however, has not yet been formally established in the Greek education system. This is because, the Ministry of Education has not yet provided any formal training on differentiation to in-service teachers as part of their professional development.

As a response to the inclusion of pupils with disabilities in the Greek education system, the Ministry of Education established co-taught classrooms, in which a special 
education teacher (SET) provides in-class support to a student with an identified disability. The main duties of these SETs involve providing one-to-one support to a student with disabilities and, in this way enhance their access to the general education curriculum. In the Greek education system, all mainstream education teachers (METs) hold a Bachelor's degree in mainstream education, while SETs hold a bachelor's degree in special education or they are qualified mainstream teachers with a masters or 400hours seminar in special education. It is worth mentioning that the Ministry of Education provides SETs with some training during their employment in co-taught classes but this training is not available to METs. Finally, it should be noted that learning assistants and health professionals are not currently employed in Greek mainstream schools.

All children with disabilities in the Greek co-taught classrooms should have a statement of SENs. SENs according to 3699/2008 Law include the categories of autism, sensory and physical disabilities, intellectual disabilities, health disorders, specific learning difficulties, and challenging behaviour. However, children who learn in cotaught classrooms are usually those who present moderate learning difficulties, such as children with high to medium functioning autism, moderate intellectual disabilities, and physical or sensory disabilities.

\section{Integration versus inclusion and the social model of disability in the school settings}

Several writers have argued for the development of pedagogical/educational practices which do not consider the education of students with disabilities in mainstream education through an individualistic/medical deficit approach, but as a process that involves changes in the context of the school through the implementation of the social model of disability (Ferguson 2008; Kugelmass 2006; Slee 2013). This move has been described as a shift from special education to a process that values diversity within a common school for all or, drawing on Vislie's (2003) argument, as a process from integration to inclusion. According to Vislie (2003), integration is associated, among other things, with the education of students with disabilities in mainstream classes through the development of special education in new integrated settings. On the contrary, educational inclusion is associated with the reconstruction of curricular provision for all students, and, according to Thomazet (2009), we should equate inclusion with differentiating practices and not with more developed integration.

Although there is no agreement on what inclusion is, many researchers agree that it is more than the placement of pupils with disabilities in the mainstream classroom (Ferguson 2008; Mitchell 2008; Thomazet 2009). Rather, as Booth and Ainscow (2011, 9) assert "Inclusion is about increasing participation for all children and adults. It is about supporting schools to become more responsive to the diversity of children's backgrounds, interests, experience, knowledge and skills”. Thus, the focus is not merely on the improvement of the skills of the student with disabilities, but mainly on the improvement of teaching for all students.

It appears that integration constitutes a response to students' disability through a categorical/medical approach in which students with disabilities have to 'adjust' themselves to the existing arrangements. This categorical approach to disability, based on the medical model, prevents progress in the field of inclusion since, according to Ainscow $(2007,3)$ 'it distracts attention from questions about why schools fail to teach so many children successfully'. A question of this type cannot be easily answered since it demands an analysis of more philosophically based elements. Thus, we argue that many elements of the Foucauldian theory can shed light to the above question by 
highlighting how the imposition of a specific identity to students with disabilities, merely constructed on their difficulties, minimize their chances for an equal and accessible education (Foucault 1982). In line with this, Runswick - Cole $(2011,115)$ questions the assumption that there has been a 'bias' towards inclusive education highlighting the need to actually 'try' inclusion than merely assuming that children with disabilities must fit in the education of the majority of the 'able' students. Consequently, in the school settings, we need to take into consideration all those factors which restrict the activities of students with disabilities, and to consider, as Thomas $(2004,580)$ argues a social relational view on disability in which 'disability only comes into play when the restrictions of activity experienced by people with impairment are socially imposed'. By drawing on the above theoretical resources, we will interpret the results of the present study in relation to students' with disabilities identity issues and to coteachers' understandings of differentiation.

\section{Differentiated instruction in single taught and co-taught classrooms}

Cook and Friend (1995) define co-teaching as the situation in which a mainstream education teacher (MET) and a SET deliver substantive instruction to a diverse, or blended, group of students in the same physical space. Even though coteaching is considered a promising practice with positive implications for all students (Murawski 2010; Thousand, Nevin, and Villa 2007), several challenges are associated with its implementation (Cook et al. 2011; Scruggs, Mastropieri, and McDuffie 2007; Stefanidis and Strogilos 2015). These challenges are closely related to the instructional actions developed by co-teachers which can promote the access of all students to the general education curriculum. Among these actions is the differentiation of the curriculum for all students with specific modifications/adaptations for students with disabilities.

DI involves responding effectively to the differences that exist among learners in the classroom. According to Tomlinson (2000), teachers differentiate when they reach out to an individual or small group by varying their teaching in order to create the best learning experience possible. The adaptations made to the curriculum are considered an essential inclusive strategy for the education of students with disabilities in the mainstream classroom. According to Janney and Snell (2006), adaptations may be curricular, instructional or alternative. Curricular adaptations refer to what is being taught (i.e. content), instructional concern alterations of the way instruction takes place (i.e. method), and alternative adaptations involve altered goals, instruction and activities. As King-Sears (2008) notes differentiation has the potential to increase the scores on high-test assessments for students with disabilities, students at-risk for school failure, typical students, and students labelled as gifted and talented in comparison to schools that promote 'one size fits all' instruction. In addition, Lee, Wehmeyer, Soukup and Palmer (2010) found that when curriculum modifications are used students with disabilities increase their engagement in academic-related responses and decrease their problematic behaviours.

Despite the perceived importance of differentiated instruction, research has indicated the absence or inconsistent use of this strategy due to a number of factors. For example, Van Tassel-Baska and Stambaugh (2005) have identified a number of obstacles that impede educators in differentiating for gifted learners in the mainstream classroom. Among these factors were the lack of content knowledge necessary to extend and differentiate the typical curriculum content areas, the lack of adequate planning time to adjust the curriculum for the gifted and talented students, their 
difficulty to locate and use effectively a range of resources, and even their perception that students do not differ in how they learn. According to Hertberg-Davis (2009) many teachers seem resilient in differentiating because they perceive it as highly time consuming. As this author notes, although teachers may become accustomed in differentiating the curriculum, they considered its initial planning off-putting, and for this reason they perceived differentiation as unrealistic or only for 'at risk' students. Similar findings have been reported by Vlachou, Didaskalou and Voudouri (2009) since in their research they identified several barriers in the use of adaptations by METs. It is interesting that among the several barriers mentioned by teachers (e.g. lack of time and resources, pressure to cover the curriculum/textbook, lack of knowledge and training, the perception that some adaptations are not feasible or they are time-consuming) was the fear of reproducing discrimination originating from the belief that «sameness» and «same treatment» ensures equality.

With regard to students with disabilities, many research studies in this area report a lack of curriculum modifications in co-taught classrooms for these students (Antia 1999; Buckley 2005; Strogilos and Stefanidis 2015; Strogilos, Tragoulia, and Kaila 2015). As Scruggs, et al. (2007) indicate, the education of students with disabilities in the co-taught class lacks appropriate teaching materials, differentiation in activities and opportunities for individualising the curriculum. McDonnell (2011) argues that progress cannot be made due to the fact that the definitions of 'accommodation' and 'modifications' are somewhat muddled in the literature.

It could, therefore, be suggested that there is currently no agreement with regard to the use and understanding of the term 'differentiated instruction' as a means to improve the quality of education and to increase the access of all students including the students with disabilities to the general education curriculum. In other words, the meaning of the term 'differentiated instruction', which is extensively used in the literature, is not clearly defined since different authors seem to give different meanings to this term. Thus, it would be interesting to identify how teachers understand the term 'differentiated instruction' by describing what sort of meaning they give to this word. In addition, even though research has shown that differentiation is not consistently used in the mainstream classrooms, there is currently little research to examine the factors that promote or hinder its development.

Thus, the aim of this study is twofold. First, to explore how co-teachers in Greek mainstream schools understand the term 'differentiated instruction', and, second, to describe the factors that affect its implementation in the co-taught classrooms.

The research questions posed are as follows:

a) How do co-teachers understand the term 'differentiated instruction'?

b) Which are the factors that influence the development of DI in the co-taught classrooms?

\section{Method}

A qualitative research investigation was deemed the most appropriate form of inquiry to explore teachers' understanding of 'differentiated instruction' and the factors that influence its implementation. DI seems to be a complex social action and as such we need to grasp the meaning that constitutes this action. As Schwandt (2000) argues, from an interpretivist point of view, social actions depend on the context and intentions of the people and 'what an action means can be grasped only in terms of the system of meanings to which it belongs' (p. 191). In order to interpret what 'differentiated instruction' means for mainstream and special education teachers, and to grasp the meaning that these teachers give to this action/phenomenon, we conducted interviews 
and observations. The teachers' opinions, experiences, and representations became the empirical basis of our interpretations (Patton, 1997). We aimed to get as close as possible to the research participants' experiences and interpret 'differentiated instruction’ through their eyes (Willing 2013), and most importantly, within their social and cultural context.

\section{Participants}

Thirty four co-taught teams (34 METs and 34 SETs) in 34 mainstream schools from five local educational authorities (LEA) participated in this study. Co-taught teams were selected from a list of co-taught classrooms given by the LEAs. We carefully selected co-taught teams with fully qualified METs and SETs working from Reception to Year 3 classrooms. We selected teams from early year settings since coteaching in Greek schools is more prevalent in these settings. Also, we felt that teaching is more flexible in early years settings, and thus DI is well justified and expected in these classrooms.

All cases were selected after personal contact with schools and parents' consent. The majority of the teacher participants were females $(n=63)$, while only 5 were males. Their mean age was $39.20(\mathrm{SD}=9.26$ ) years old and they had a mean number of 12.03 $(\mathrm{SD}=9.09)$ years of teaching experience and $1.92(\mathrm{SD}=1.70)$ years of co-teaching experience. Twenty four SETs indicated that they had training on DI in their undergraduate studies and only three METs indicated that they had in-service training of this kind. However, it is worth mentioning that when we asked these teachers to describe this training, they briefly referred to the development of individual education programmes for students with disabilities. These thirty four investigated co-taught classrooms included nineteen students with autism, five students with mild intellectual disability, four students with physical disabilities, two students with hearing impairment, two students with visual impairment, and two students with attention deficit hyperactivity disorder.

In implementing this project, four researchers collected data. Two researchers took over ten cases, and the other two seven each. Data collection lasted six months during which several online meetings took place in order to make sure that the four researchers follow the same procedures in the collection of data and remain focused on the aims of the study.

\section{Data collection and analysis}

Sixty eight semi-structured interviews and 57unstructured naturalistic observations were used for data collection. Each co-teacher was interviewed separately at the school at the end of the school day. During the interviews, co-teachers were asked to describe their understanding with regard to 'differentiated instruction' and to share the factors which affect its implementation. Interviews were guided by a semistructured schedule designed to elicit information about: the respondents' understanding of differentiation, factors which influence the implementation of DI, roles and collaboration between co-teachers, instructional practices that they commonly use in the classroom and proposed improvements. All interviews lasted from 30 to 45 min, were recorded on audio-tape and later transcribed.

All thirty four pairs of teachers (METs and SETs) were observed at least on one occasion. In some cases, two unstructured naturalistic observations took place in each co-taught classroom in a core subject (e.g. literacy, numeracy, science). Each observation lasted from 45 to 90 minutes. An unstructured observation protocol (i.e., a written description of teachers' actions) was developed to guide the recording of the 
relevant evidence. Since we were interested to understand the behaviours of the coteachers and not to test our pre-conceived ideas about their behaviours, an unstructured observation tool was chosen as more appropriate in relation to a more structured one. In this protocol, all observers described the actions of the co-teachers with regard to the process of DI for all students including the students with disabilities. In particular, we recorded information about the content of the lesson as well as the teaching strategies (i.e., direct instruction, group-work, individual teaching) that co-teachers implemented to fulfil the requirements of each lesson, the resources/ materials used (e.g. calculators, symbols, different reading texts) and any specific support (e.g. extra time, individual assistance) that the co-teachers provided for individual students. The focus of the observations was to look how the perceptions of the co-teachers (as elicited through the interviews) are reflected in their praxis.

Two researchers took over responsibility for analysing all interviews and observations. Both tools were piloted in three co-taught classrooms and a few minor changes were initiated after the pilot phase. To analyse the interview data we followed the basic principles of grounded theory, as described by Charmaz (2008): open coding, focused coding, memo writing and theoretical sampling for the development of emerging theory. Using the systematic coding principles advocated by Charmaz, all the interviews were compared for similarities and differences.

In particular, two members of the research team transcribed all interviews into text and read them many times in order to obtain a sense of the topics that were embedded in the data. Then the researchers produced the initial codes depending on the different meanings of each phrase, line or paragraph of the text (i.e. initial coding: line by line coding). At this stage, we assigned codes to specific phases, lines or paragraphs in order to elicit the specific descriptions and beliefs given by the co-teachers about DI and the factors that promote or hinder its development. A list of all the extracts of the data was made for all the different codes and for each participant teacher. We grouped the different codes to create categories and subcategories and then we compared all the different categories to remove redundant categories and put together categories with similar meanings (i.e. focused coding).

As a result, we elicited three main categories (or themes) at this stage: 'understanding of disability', 'understanding of DI' and 'factors that influence the development of DI'. The 'understanding of DI' was an unexpected through-thread category and it was mainly used in relation to the 'understanding of DI' category. Thus, for the first and second main categories, we identified two subcategories (i.e., 'DI as a child oriented activity' and 'DI as a context oriented approach'), while for the third main category (i.e., 'factors that influence the development of DI'), we identified six subcategories (i.e., 'lack of knowledge, 'limited collaboration', large number of students per class', rush to cover the class curriculum, stigmatization', and lack of space'). We compared the final subcategories to find links between the different cotaught classrooms and between mainstream and special education teachers (i.e. theoretical sampling). A constant comparison between the main categories led to the development of a theory in which the understanding of DI is highly associated with the understanding of disability and the factors which influence its implementation (see results). This means that our constant comparison of the above categories and subcategories helped us to identify the hidden meanings in co-teachers' accounts with regard to their practices and their beliefs about disability. By so doing, we developed a theory in relation to DI and disability grounded on the data and not on our pre-conceived ideas. 
Complementary to the grounded theory analysis followed in the interviews, the analysis of the observations included the use of pre-existing categories on the different types of adaptations that were available in the related literature. In particular, the analysis of the observations included the counting and description of mainstream and special education teachers' actions with regard to DI. We mainly focused on the types of adaptations that co-teachers employed for students with and without disabilities. Following Janney and Snell's (2006) framework, the adaptations were divided into curricular, instructional, or alternative. In particular, curricular adaptations alter the content of what is taught through supplementary, simplified, and alternative adaptations. Instructional adaptations alter how content is taught, how learning is demonstrated and how students can respond. According to Lee, Soukup, Little, and Wehmeyer (2009), these adaptations also include the personal support provided to a student by an adult, support by a classmate, adaptations at the space of the class, use of supportive technology, provision of extra time, support when someone else is writing for the student with disabilities etc. Alternative adaptations alter the goal, the instruction, and the activity and they include alternative/parallel activities, remedial instruction and functional skill instruction (Janney and Snell 2006).

To ensure reliability in the analysis of the observations and interviews, two researchers worked together in analysing the first twelve interviews and observations. All codes, categories and subcategories were agreed between the two researchers before included in the first stages of the analysis. After they reached a very high level of agreement in the identification of categories and subcategories, they started working separately in the analysis of the interviews and observations. Although the majority of the data were analysed separately by the two researchers, they kept collaborating for several weeks to deal with emerging issues and the inclusion of new categories and subcategories in the analysis of the data.

\section{Results}

The participants in this study provided a variable picture of how DI is understood and implemented in their classrooms. This inconsistency could be attributed to a confused understanding of the conceptualization and implementation of DI. In addition, even though all the participants acknowledged the importance of DI, they provided a number of contextual factors which hinder its implementation.

\section{Understanding differentiated instruction}

Teachers' accounts revealed that they understand DI in two interdependent ways. The first refers to the understanding of DI as a 'child's deficit oriented activity' and not a 'context oriented approach' in which the curriculum is adapted/ modified. The second refers to the extensive use of 'instructional adaptations/ modifications' in relation to the limited use of 'curricular' or 'alternative adaptations'. These two ways are closely interrelated since both focus on changes to help students with disabilities adjust themselves to the class curriculum following a medical approach to disability.

\section{Differentiation as a 'child's deficit oriented activity'}

Many co-teachers (17 METs and 17 SETs) referred to DI as a process which mainly focuses on individual teaching to assist students with disabilities 'fulfill the requirements of the class'. Throughout this study, the SETs' and METs' accounts placed a heavy emphasis on the individual difficulties presented by the students with disabilities in relation to the common class curriculum. 
"I use differentiation because a child with autism can't understand the new knowledge in the same way as the other students. He needs to get himself adjusted to the class curriculum" (SET)

"I use differentiation for some children that are immature. They need a different approach" (MET)

"Differentiation is used for children that need more help" (MET)

"I use differentiation because he doesn't seem to understand the teacher of the class" (SET)

The emphasis on the deficits of the students with disabilities seemed to affect the type of adaptations that were made by the majority of co-teachers (both SETs and METs). It was evident from our observations that individual assistance was extensively used in relation to other effective teaching strategies (e.g. modified content, participation in group activities). In almost all observations, SETs spend most of their time sitting next to the students with disabilities to help them follow the same undifferentiated curriculum with the rest of the class.

\section{Differentiation as a 'context oriented approach'}

Very few teachers (2 METs and 4 SETs) appeared to understand differentiation as 'a context oriented approach' in which emphasis is given on differentiating the curriculum for all students. These few teachers held an understanding of differentiation as a flexible strategy where emphasis is provided on altering the content, the methods and the outcomes for all students, including those with disabilities.

"Differentiation is not only for Giannis but it is important for all the students in the class. Differentiation is when you are trying to adapt to the needs and desires of all the students. You have to work hard every day in order to find materials that are interesting for everyone” (MET)

"I am trying to make sure that all students can learn. I believe that the activity sheets should be at different levels because there aren't only students with SEN that have difficulties. All students need a differentiated approach' (SET)

"Differentiation is when we differentiate the goals of the national curriculum in order to adapt them to the needs of every student" (SET)

\section{Differentiation as instructional adaptation}

The second way that co-teachers understand DI is according to the type of modifications/adaptations (i.e. curricular, instructional, alternative) that could be used in the class. The majority of mainstream and special education teachers referred to DI as a process related mainly with 'instructional adaptations', whereas the objectives and the teaching content remain the same for all students in the class.

"Differentiation is when an activity is adapted in order to be more suitable for the student, but the goals remain the same" (MET)

"Differentiation refers to different methods" (MET) 
"Differentiation is when you try to teach the same content to a student but with different ways. For example, you can choose to teach the same content by using the computer, the PowerPoint or different ways for communication such as PECS or TEACCH”'(SET)

"Differentiation is when we have the same activity but we try to differentiate the way we teach the students depending on their needs" (SET)

As co-teachers described it, their effort was to help the students with disabilities by mainly providing 'instructional' rather than 'curricular' or 'alternative' adaptations. In particular, the co-teachers restricted these 'instructional adaptations' to the provision of individual assistance through the use of simplified language and extra time provided to these students. In particular, 28 SETs and 6 METs referred to individual assistance as their main differentiation strategy. In addition, in the observations we noted 200 (78.1\%) 'instructional', 54 (21.1\%) 'curricular' and only two 'alternative' (0.8\%) adaptations. The following observational notes support the prevalence of 'instructional' adaptations:

"The MET is asking more questions to John (student with disabilities) and she is giving him more time to answer. She is also praising him every time he answers"

"The SET is repeating to Maria (student with disabilities) the instructions that the MET is giving to the other students in the class"

"The SET is repeating the question of the MET and she is showing with her finger different pictures in order to help George (students with disabilities) concentrate at a specific picture each time"

"The SET is sitting with the student with disabilities and is trying to use simplified language to explain the activity"

In contrast to the dominant implemented adaptations outlined above, we exceptionally observed a few 'curricular adaptations' for the students with disabilities. In particular, we observed only seven METs and seventeen SETs to implement 'curricular adaptations' for these students. Two indicative examples are the following:

"The MET asked the whole class to draw a face with a particular emotion and write the correct emotion next to the face. At the same time, the SET used a puzzle with emotions and asked the child with disabilities to match the face with the correct emotion"

"The students read information about two specific animals. The SET had prepared a different text with information about the favourite animal of the student with disabilities”

It is worth mentioning that in our observations we did not record any adaptations/modifications for the students without disabilities. These students had to work on the same undifferentiated materials through the same procedures in order to produce the same results.

\section{Factors influencing differentiated instruction}


Co-teachers described several barriers that prohibited the use of DI. The most important ones were the lack of training, the problems in collaboration between coteachers, the large number of students per class, their commitment to deliver the undifferentiated NC, the lack of space and stigmatisation. It was evident across cases that these factors influenced the development of DI as an important inclusive activity.

\section{Limited knowledge on implementing differentiated instruction}

Seventeen out of 34 METs and 13 out of 34 SETs expressed serious concerns about their limited knowledge on differentiating the curriculum. They believed that specific training on curriculum adaptations/modifications is needed for educating all students and especially those with disabilities. It is indicative that almost all METs expressed their unpreparedness to educate students with disabilities in their classrooms

"I don't have knowledge about using differentiation, I have never been trained" (MET)

"I haven't been trained about DI. They ask us to implement it but they haven't trained us. I am trying to find information alone" (MET)

"I need more training in a more practical way. We just learned the theory at the university" (SET)

"We want to attend some seminars that are about the practical side of differentiation. If you are interested, you can find and read things alone but the practical side is more difficult” (SET)

\section{Limited collaboration between co-teachers}

Throughout this study, the SETs and METs provided several examples of their limited collaboration in designing and implementing differentiation. From both interviews and observations, it was evident that METs considered that their responsibility was to provide whole class activities whereas SETs undertook the responsibility to differentiate instruction for the students with disabilities.

"We need to be trained because we find it hard to collaborate. It's important for all the teachers to understand that SETs are second teachers and their role is not just to assist the students with disabilities. The SETs must design the whole class activities together with the MET. Unfortunately, I haven't found this kind of collaboration in any school." (SET)

"I feel that SETs shouldn't be in the class in order to help only the children with disabilities. I think that this is the view of many METs. They don't like when SETs take the initiative to design something for the whole class" (SET)

"It's difficult for the METs to accept that we are both teachers of the class. A MET must be very open-minded to accept it. There is unfamiliarity with this topic" (SET)

"The SET is responsible only for the student with disabilities. Of course, I am responsible for the design and implementation of the whole class activities" (MET) 
"We are not designing the activities together because she is responsible for the students with disabilities. We have different goals and the curriculum is different. We also receive guidance from different counsellors" (MET)

It was evident that the METs did not collaborate with their SETs counterparts to differentiate instruction as they considered differentiation only the SETs' responsibility. METs justified the above inconsistency by expressing their concerns at the gaps in their knowledge and skills with regard to differentiating instruction for these students.

"I believe that SET should be responsible for the design and implementation of DI because she has more knowledge than me" (MET)

"The SET knows better these children and she has more ideas. I think she must be responsible for the adaptations" (SET)

The above different understandings about the co-teachers' responsibilities obviously had a negative impact on establishing an effective collaboration between METs and SETs. This negative impact was mainly evident in designing and implementing adaptations and modifications for all students in the class.

\section{Large number of students per class}

A remarkable similarity across cases was elicited from both the interviews and observations, with regard to the barriers in implementing DI, was the large number of students per class. All co-teaching pairs expressed their concerns on the effectiveness of DI when the number of students in a class is large. Both METs and SETs' accounts were indicative of the need to decrease the ratio between teachers and students in the class in order to enhance the quality of participation for all students in mixed-ability groups.

"It is possible to implement differentiations when you have smaller number of students. When you have a class with 24 students and three students with disabilities that each one needs a different adaptation every day, it's very difficult” (MET)

"The number of the students without disabilities should be reduced. You can't have two or three students with autism and 20 more typically developing students" (SET)

\section{Rush to cover the NC}

The commitment of METs to fully deliver the undifferentiated NC within specific time limits was regarded by co-teaching pairs as a restrictive element to differentiate instruction effectively. Sixteen METs expressed their concerns with regard to the limited time to deliver the curriculum underlining the requirements imposed by the Ministry of Education. METs, in particular, indicated that DI is time-consuming and impossible to implement given the time requirements to deliver the NC. In addition, all SETs reported that they experienced pressure from the METs when they suggested the implementation of DI.

"One factor that hinders the use of adaptations is the curriculum. We have to go on, not only because we have to finish the book, but because there are specific goals that must be fulfilled before the students go to the next class" (MET) 
"We can't do more things because there is pressure to finish the curriculum. There is not enough time" (MET)

"There is lots of pressure because of the lack of time. It is very sad that METs don't meet the needs of the students with disabilities. They are "religious" about following the NC. The MET just explains a topic and then he goes to the next one. The students can't follow her. The pressure of the time affects both of us (SET and student with disability) (SET)

\section{Stigmatization}

The fear that differentiation may lead to the stigmatization of the students with disabilities was regarded by one MET as a restrictive element to differentiate instruction. In addition, one SET mentioned that a mother does not allow her to differentiate the curriculum for her son since this mother considered differentiation as a form of discrimination. Interestingly, this child was also refusing to work on differentiated activities.

"I don't use different activities for Eleni. I don't want to make her feel embarrassed and different from the other students in the class. I am worried that the other students may realize that there is something different with her and this may affect her negatively. Differentiation must be done very carefully to avoid stigmatizing her"

"The mother of the child doesn't let me to use any adaptations. She wants her son to do exactly the same things as all the other students in the class...her son doesn't accept to do something different. He is shouting, you can't give him something different"

\section{Lack of space}

The lack of space was another contextual factor that prohibited the use of DI. According to 6 METs and 4 SETs, there wasn't enough space in the class to implement DI. It was evident from two teachers' accounts that they were confusing DI with individual instruction, as they were worried about the lack of space to work 1:1 with the student with disabilities.

"The main problem is that the class is too small and I can't take him to a corner for 1015 minutes to work on something meaningful for her. We are cramped for room" (SET)

"We don't have enough space. There is not a room, a different table in order to sit alone with the students with disabilities and implement an adaptation. There are also other students. We have 23 students and everyone will sit together. But if the class was bigger, the SET could take him (student with disabilities) to a more isolated place and do something different" (SET)

\section{Discussion}

The practice of differentiation which we observed in this study can hardly correspond to the types of differentiation described in theory (Tomlinson 2003; Janney and Snell 2006). The majority of co-teachers understood differentiation as an individual and not a context-oriented approach suitable for all students. In addition, the prevalence of instructional adaptations over curricular or alternative, and the implementation of 
differentiation as a child's deficit oriented approach are two interrelated themes with regard to the understanding of differentiation. The majority of co-teachers placed a heavy emphasis on meeting individual difficulties of the students with disabilities and not on curriculum adaptations/modifications for all students in the class. Thus, differentiation is perceived and practiced as a 'child's-deficit' approach rather than a 'context- oriented' approach.

Co-teachers reported a great number of factors which, in their view, prohibited the implementation of DI for all students. These factors include their limited knowledge to implement differentiation, the limited collaboration between co-teachers, the large number of students per class and the lack of space, the fear of stigmatization, and their need to cover the NC. It is indicative that teachers in the Greek co-taught classrooms identified similar factors that hinder the implementation of DI to those that have already been identified in the international literature (Hertberg-Davis 2009; Van Tassel-Baska and Stambaugh 2005). This evidence shows that DI creates pedagogical dilemmas and misunderstandings that cross different educational systems and, in order to respond to these issues, practitioners need, as King-Sears $(2009,61)$ contends, 'to maximize the use of differentiation techniques so that all students progress'.

Even though co-teachers noted important barriers which prevent the implementation of DI, these barriers alone cannot adequately justify the limited DI in the investigated co-taught classrooms. Instead, we argue that it is the teachers' medical understanding of disability that affects their choice to follow a child's-deficit approach through instructional adaptations. Put it simply, the contextual barriers alone cannot possibly justify the limited differentiation but rather the way disability is understood seems to be the main force to this end.

The respondents' understanding of differentiation is closely related to their understanding of disability and has a great number of implications with regard to the students' identity formation and their associated social needs. If we are to proceed to a deeper analysis of the way co-teachers understand differentiation and consequently follow 'a child's oriented approach' as mentioned above, we need to look beyond the descriptive surface in order to provide more philosophical interpretations that could better justify the co-teachers' decisions. In this way, although we do not disregard the factors mentioned to hinder differentiation, we argue that misconceptions and misunderstandings about differentiation need to be interpreted through the exploration of established views on the construction of specific identities for students with disabilities originating from the medical model.

\section{"Disabling" differentiated instruction}

The way co-teachers construct their understanding of differentiation seems to be dependent on how teachers construct the children with disabilities' identity. This dependency can be explained on the basis of Foucault's theory which points out how the 'medical gaze' becomes a technique to exercise power and to control individuals (Foucault 1982). The teachers in the investigated co-taught classrooms seem to have assigned students with disabilities a specific identity according to their diagnosed impairment. As a consequence, co-teachers chose to implement basic adaptations (i.e. instructional adaptations) mainly for these students, which could not fully promote their inclusion. Viewed from a Foucauldian perspective (Foucault 1977), co-teachers gave students with disabilities specific identities according to their impairments as described by the medical model. It seems that such an approach was greatly hindering the consideration of the students' social needs, which in turn, had a negative effect on the promotion of their inclusion (Foucault 1977). The mechanisms of surveillance as 
initially identified by Foucault and more recently applied by Allan (1999) in the field of special education, can also provide a good interpretation of how co-teachers construct the identity of the students with disabilities (Allan 1996).

In our view the co-teachers' opinions are connected with the construction of an identity based on the 'normal'. As argued by Foucault $(1977,184)$, the notion of 'normal' entered the educational organisations as a 'principle of coercion in teaching and as an instrument of surveillance'. Thus, as Allan (1996) argues, students with disabilities are defined in terms of normality, in a way that every student who is deemed by professionals to require special treatment, needs to receive diagnosis. According to this author, students with disabilities who do not receive a diagnosis are considered disadvantaged. In this way, the process of diagnosis is considered necessary, even "valued", in order to distinguish the children with disabilities from their typically developing peers.

The above are clearly connected with the practices applied in the investigated schools for students with disabilities. Co-teachers view the students with disabilities from a narrowly-defined standpoint of 'normality' thus aiming to eradicate the differences of these children. Even though co-teachers hold the view that differentiation could be beneficial to the learning of students with disabilities, their practices do not reflect the principles of inclusion. Indeed, co-teachers restrict their teaching practice to the implementation of individual teaching in order for students with disabilities to overcome their difficulties and adjust themselves to the undifferentiated class curriculum. In so doing, special education principles dominate their teaching. Even though, co-teachers consider instructional adaptations as the means to promote the students with disabilities' inclusion, their instruction resembles with integrative rather than inclusive practices.

Applying the Foucauldian theory to the present empirical research, it seems that the participating co-teachers' practices could be seen as fundamentally paradoxical given the absence of distinctive special pedagogies for pupils labelled as having SEN (Lewis and Norwich, 2007). Nonetheless, there still exists in educational circles the assumption that there is a group of children, identified as having disabilities or SEN, who belong to a different pedagogical category, and therefore require specialist teaching in order to cope with the demands that mainstream schools impose to 'able' students. Goodley and Runswick-Cole (2010) in their critical analysis of how play can be emancipated for disabled children, so as not to be the means to assessment and development, propose the deconstruction of the use of developmental psychology and the disconnection of play with normality in order for children with disabilities to repossess play. In line with the above argument, we also suggest that teachers need to deconstruct their perceptions about inclusive education and to disconnect the type of adaptations they chose to include in their teaching with specific impairments. It seems that despite teachers' willingness to use differentiation as an effective pedagogical practice, they currently provide types of adaptations that mainly aim to help the students with disabilities to adjust themselves to the requirements of the 'normal' mainstream class.

It appears that practice in Greek co-taught classrooms basically focuses on special education principles, and, as Vislie (2003) argues, if we are to promote inclusion, we need to bring new insights on the deconstruction and reconstruction of disability. So far, this accords with what constitutes disability for the co- teachers in this study. Co-teachers seem to be in a vicious circle in which they conceive disability as an impairment and impairment as an obstacle for these students' access to the undifferentiated class curriculum. Thus, the consideration of disability solely as an 
impairment seems to affect the implementation of DI and to restrict these students' school activity. Goodley (2001) argues for a reconsideration of impairment in relation to learning difficulties. According to this author learning difficulties need to be recognized as a socio-cultural phenomenon and not only as a natural impairment. In the current study, co-teachers seem to understand students' learning needs as an impairment, as a biological deficit capable of preventing the implementation of flexible teaching approaches. In this respect, DI is solely associated with individual teaching, which in the teachers' mindset is the only suitable teaching strategy for students with disabilities, and consequently they unintentionally contribute to the 'disabling' of DI. In other words, these teachers 'undermine' the effectiveness of DI and its association with responsive teaching by believing that this strategy is only suitable for students with disabilities. As a result, the consideration of disability through the medical model, in conjunction with several misunderstandings about DI, seems to negatively influence the education of students with and without disabilities in the co-taught classes.

Thomas' (2004) interesting analysis of disability seems to strengthen our interpretations since the majority of co-teachers appear to equate disability with restrictions of activity in the school settings without acknowledging that disability is also associated with social oppression or systematic social exclusion. To this end, coteachers attribute the lack of DI to contextual factors (e.g., the large number of students per class, the pressure to cover the undifferentiated NC) and consider that any school reform needs to be imposed from the Ministry of Education (i.e. a top-down approach). In so doing, they fail to notice that teachers also play a vital role in creating the conditions of a school reform. Even though it appears that some teachers in our study embrace the principles of the social model (in the sense of acknowledging the importance of school reform to respond to the diverse needs of all students) they actually do not consider that they themselves are part of this school reform. By doing so, they impose a social and, we might say, pedagogical oppression to their students. Goodley and Roets $(2008,243)$ argue that critical educational researchers need to theorize and deconstruct impairment rather than to ignore it. This challenge is crucially important when interpreting the results of the present study as it seems that co-teachers 'stereotypically associate forms of personhood with particular impairments' when constructing a pre-defined type of DI only for students with disabilities. Consequently, as Liasidou (2013) argues, students with disabilities experience compounded and overlapping forms of oppression that need to be addressed through appropriate education policy and practice.

\section{Implications for practice}

The fact that co-teachers understand differentiation as a child's deficit oriented approach raises great concern about how disability is constructed and thus how the education of students with disabilities is perceived. In addition, the lack of differentiation for students without disabilities is also an issue of great concern. We contend that the pre-service (undergraduate) education of teachers and their role in the classroom (whether as a mainstream or special) seem to influence their practice in terms of providing limited adaptations only for students with disabilities and no adaptations for the rest of the students.

In order for co-teachers to implement substantive DI, they certainly need to be involved in a deconstructive process of their thinking and actions. As O'Leary (2002, 16) argues, teachers need to be engaged in a process of modifying and transforming their way of thinking and acting both towards 'themselves and others'. 
In other words, if we are to relate postmodern thinking to the current research, it seems that co-teachers need to deconstruct how they acquire knowledge relative to inclusive education issues and in particular DI. This means that co-teachers need training to adapt the basic principles of postmodern thinking (Scott and Usher 1996). Also, as Allan (2004) proposes, teachers need to empirically engage with deconstructive processes in order to proceed to a substantial reconceptualization of disability. Co-teachers need to embrace the value of reflecting upon their own views as well as on situational complexities, and be willing to deconstruct established beliefs. Under a postmodern thinking, co-teachers need to learn to become flexible, to permit the shift of meaning in situations taken for granted (e.g. students with disabilities learn better through individual teaching) and hence to encourage an alternative construction of education reality. To this end, it seems necessary for co-teachers to adopt a more flexible stance towards the meaning they give to DI taking into consideration the complexities of the education of all students in the co-taught classrooms.

In particular, pedagogical changes are necessary in the design of the pre-service and in-service education for both special and mainstream education teachers. These changes need to address issues relative to the deconstruction of disability as an impairment of the person, and, on the contrary, to the construction of disability as a social issue. In addition, undergraduate and in-service courses should focus on the development of DI as an effective strategy for all students, and not only for students with disabilities. This will provide better opportunities for the inclusion of all students in the co-taught classroom.

As Allan (2004) argues, postmodern thinking as well as Foucault's ethics can actually be elaborated with regard to inclusive education in the sense that teachers can actually redefine their thinking and thus their practices. Thus, differentiated teaching needs to be implemented as a strategy nurtured by a theory which does not equate disability with restricted activity and pedagogical exclusion. Pedagogical changes need to be taken in order for co-teachers to recognize that disability is considerably associated with oppression and exclusion, socially and pedagogically, and thus differentiated teaching can be implemented as the means to eliminate predominantly oppressive and exclusive practices.

\section{Limitations and future research}

In the limitations of this study we would include some of the challenges associated with qualitative research. Specifically, the purposive sample employed does not allow any generalization to wider co-teaching teams, and thus our interpretations are context specific. Moreover, although substantial efforts were made to ensure the necessary prolonged engagement in the field, our observations in the investigated cotaught classrooms were limited to one or two occasions. In addition, the majority of the teachers in our sample lacked appropriate training on DI, and thus we recognize that our results were well expected with regard to the understanding of this approach. DI in Greek co-taught classrooms is still emerging and further research is needed to better understand the gap between theory and practice, and what is actually needed to bridge a gap of this kind. Even though co-teachers in this study talked positively about DI, we detected several misunderstandings and poorly implemented practices. This means that future research needs to provide further understanding of how co-teachers conceive the term 'differentiated instruction' especially in countries with a long tradition of this approach. 


\section{References}

Ainscow, M. 2007. “Taking an inclusive turn.” Journal of Research in Special Educational Needs 7(1): 3-7. DOI:10.1111/j.1471-3802.2007.00075.x.

Allan, J. 2004. "Deterritorializations: Putting postmodernism to work on teacher education and inclusion”. Educational Philosophy and Theory, 36(4):417-432.

Allan, J. 1999. Actively Seeking Inclusion: Pupils with Special Needs in Mainstream Schools. UK: Falmer Press.

Allan, J. 1996. "Foucault and Special Educational Needs: A 'box of tools' for analysing children's experiences of mainstreaming,” Disability \& Society, 11:2, 219234, DOI: 10.1080/09687599650023245

Antia, S. D. 1999. "The roles of special educators and classroom teachers in an inclusive school." Journal of Deaf Studies and Deaf Education 4: 203-214. DOI:10.1093/deafed/4.3.203

Booth, T., and M. Ainscow. 2011. Index for inclusion: developing learning and participation in schools. CSIE: Bristol.

Buckley, C. 2005. "Establishing and maintaining collaborative relationships between regular and special education teachers in middle school social studies inclusive classrooms.” In Advances in learning and behavioral disabilities: Vol. 18. Cognition and learning in diverse settings, edited by Thomas E. Scruggs, \& Margo Mastropieri 153-198. Oxford, UK: Elsevier.

Charmaz, K. 2008. "Grounded theory. "In Qualitative psychology: A practical guide to research methods, edited by Jonathan A. Smith, 81-110. London: Sage

Cook, L., and M. Friend. 1995. "Co-teaching: guidelines for creating effective practices.” Focus on Exceptional Children, 15: 67-71.

Cook, L., K. A. McDuffie-Landrum., L. Oshita., and S. Cotheren-Cook. 2011. Coteaching for students with disabilities: a critical analysis of the empirical literature. In Handbook of special education, edited by James P. Kauffman, \& Daniel, P. Hallahan, 147-159, London: Routledge.

Ferguson, D. L. 2008. "International trends in inclusive education: The continuing challenge to teach each one and everyone." European Journal of Special Needs Education, 23(2): 109-120. DOI: 10.1080/08856250801946236.

Florian, L. 1998. "An examination of the practical problems associated with the implementation of inclusive education policies.” Support for Learning, 13(3): 105-108. DOI:10.1111/1467-9604.00069.

Foucault, M. 1977. Discipline and Punish. London: Penguin. 
Foucault, M. 1982. The Subject and Power. In Beyond Structuralism and Hermeneutics, edited by Hubert L. Dreyfus and Paul Rabinow, 125-145. Brighton: Harvester.

Goodley, D. (2001). 'Learning difficulties', the social model of disability and impairment: challenging epistemologies. Disability \& Society, 16(2), 207-231.

Goodley, D., \& Roets, G. (2008). The (be) comings and goings of 'developmental disabilities': The cultural politics of 'impairment'. Discourse: Studies in the Cultural Politics of Education, 29(2), 239-255.

Goodley, D., \& Runswick-Cole, K. (2010). Emancipating play: Dis/abled children, development and deconstruction. Disability \& Society, 25(4), 499-512.

Hertberg-Davis, H. 2009. "Myth7: Differentiation in the Regular Classroom Is Equivalent to Gifted Programs and Is Sufficient: Classroom Teachers Have the Time, the Skill, and the Will to Differentiate Adequately.” Gifted Child Quarterly 53: 251253. DOI:1177/0016986209346927.

Janney, R. E., and M. E. Snell. 2006. "Modifying schoolwork in inclusive classrooms.” Theory into Practice 45(3): 215-223. DOI:10.1207/s15430421tip4503_3.

King-Sears, M. E. 2008. "Facts and fallacies: Differentiation and the general education curriculum for students with special educational needs.” Support for Learning 23(2): 55-62. DOI:10.1111/j.1467-9604.2008.00371.x.

Kugelmass, J. W. 2006. "Sustaining cultures of inclusion: The value and limitation of cultural analyses.” European Journal of Psychology of Education 21(3): 279-292. DOI:10.1007/BF03173416.

Law 3699/2008. Special education of persons with disability or special educational needs. FEK199/2 October.

Lee, S., M. L Wehmeyer., J. H. Soukup., and S. B. Palmer. 2010. "Impact of curriculum modifications on access to the general education curriculum for students with disabilities.” $\quad$ Exceptional $\quad$ Children $76 \quad$ (2):213-233. DOI:10.1177/001440291007600205.

Liasidou, A. 2013. "Intersectional understandings of disability and implications for a social justice reform agenda in education policy and practice”, Disability \& Society, 28(3): 299-312. DOI: 10.1080/09687599.2012.710012.

McDonnell, J. 2011 'Instructional context'. In Handbook of special education, edited by James P. Kauffman, \& Daniel, P. Hallahan, 532-543, London: Routledge.

Mitchell, D. 2008. What Really Works in Special Needs and Inclusive Education: Using Evidence- based Teaching Strategies?. London: Routledge.

Murawski, W. W. 2010. Collaborative teaching in elementary schools. Making the coteaching marriage work! California: Corwin. 
Nind, M., and J. Wearmouth. 2006. "Including children with special educational needs in mainstream classrooms: implications for pedagogy from a systematic review." Journal of Research in Special Educational Needs 6(3): 116-124. DOI:10.1111/j.14713802.2006.00069.x.

O’Leary, T. 2002.Foucault and the Art of Ethics. London. New York, Continuum.

Pandeliadou, S., and V. Argyropoulos. 2011. Special education: From research to educational practice. Athens. Pedio.

Patton, M. Q. 1997. Qualitative evaluation and research methods (2nd ed.). Thousand Oaks CA: Sage.

Pedagogical Institute. 2011. Curriculum for the preschool classes. $2^{\text {nd }}$ Part. Available at: http://ebooks.edu.gr/new/ps.php (accessed 24-03-2016).

Rix, Jonathan, Sheehy, Kieron., Fletcher-Campbell, Felicity., Crisp, Martin., and Amanda Harper: 2013. "Exploring provision for children identified with special educational needs: an international review of policy and practice.” European Journal of Special Needs Education 28(4): 375-391. DOI:10.1080/08856257.2013.812403.

Runswick-Cole, K. (2011). Time to end the bias towards inclusive education?. British Journal of Special Education, 38(3), 112-119.

Schwandt, T. A. 2005. Three Epistemological Stances for Qualitative Inquiry. In N. K. Denzin, \& Y. S. Lincoln (Eds.), Handbook of Qualitative Research (3rd ed.). London: Sage Publications.

Scott, D. and R. Usher. 1999. Researching Education, Data, Methods and Theory in Educational Inquiry. London:Cassell.

Scruggs, T. E., M. Mastropieri., and K. A. McDuffie. 2007. "Co-teaching in inclusive classrooms: a metasynthesis of qualitative research.” Exceptional Children 73(4): 392416. DOI:10.1177/001440290707300401.

Scruggs, T., and M. Mastropieri. 1996. Teacher perceptions of mainstreaming/ inclusion, 1958-1995: a research synthesis. Exceptional Children, 63(1): 59-74. DOI:10.1177/001440299606300106.

Slee, R. 2013. "How do we make inclusive education happen when exclusion is a political predisposition”? International Journal of Inclusive Education 17 (8): 895-907. DOI:10.1080/13603116.2011.602534.

Smyth, Fiona., Michael, Shevlin., Buchner, Tobias., Gottfried, Biewer., Flynn, Paula., Latimier, Camille., Šiška, Jan., Toboso-Martín, Mario., Rodríguez Díaz, Susana., and Miguel A V Ferreira. 2014. "Inclusive education in progress: policy evolution in four European countries." European Journal of Special Needs Education 29(4): 433-445. DOI:10.1080/08856257.2014.922797. 
Stefanidis, A., and V. Strogilos. 2015. "Union Gives Strength: Mainstream and Special Education Teachers' Responsibilities in Inclusive Co-taught Classrooms.” Educational Studies 41 (4): 393-413. doi:10.1080/03055698.2015.1018872.

Strogilos, V. 2012. “The Cultural Understanding of Inclusion and its Development within a Centralised System.” International Journal of Inclusive Education 16 (12): 1241-1258. doi:10.1080/13603116.2011.557447.

Strogilos, V., and A. Stefanidis. 2015. "Contextual Antecedents of Co-teaching Efficacy: Their Influence on Students with Disabilities' Learning Progress, Social Participation and Behaviour Improvement.” Teaching and Teacher Education 47: 218229. doi:10.1016/j.tate.2015.01.008.

Strogilos, V., E. Tragoulia, and M. Kaila. 2015."Curriculum Issues and Benefits in Supportive Cotaught Classes for Students with Intellectual Disabilities.” International Journal of Developmental Disabilities $61 \quad$ (1): 32-40. doi:10.1179/2047387713Y.0000000031.

Thomas, C. 2004. "How is disability understood? An examination of sociological approaches." Disability \& Society 19(6): 569-583. DOI:10.1080/0968759042000252506.

Thomazet, S. 2009. "From integration to inclusive education: does changing the terms improve practice?” International Journal of Inclusive Education 13(6): 553-563. DOI:10.1080/13603110801923476.

Thousand, S., A. I. Nevin, and R. A. Villa. 2007. Collaborative teaching: a critique of the scientific evidence. In The Sage handbook of special education, edited by Lani Florian, London: Sage.

Tomlinson, C. A. 2003. Differentiating instruction for academic diversity. In Classroom teaching skills, edited by James M. Cooper, 149-180. Boston: Houghton Mifflin.

Tomlinson, S. 2005. Education in a post welfare society. UK: McGraw-Hill Education.

Van Tassel-Baska, J., and T. Stambaugh.2005. "Challenges and possibilities for serving gifted learners in the regular classroom.” Theory Into Practice 44(3):211-217. DOI: 10.1207/s15430421tip4403_5.

Vislie, L. 2003. "From integration to inclusion: focusing global trends and changes in the western European societies." European journal of special needs education 18(1): 17-35. DOI: 10.1080/0885625082000042294.

Vlachou, A., E. Didaskalou., and E. Voudouri. 2009. Mainstream teachers instructional adaptations: implications for inclusive responses. Journal Revista de Educacion 349:179-203.

Willig, C. 2013. Introducing qualitative research in psychology: Adventures in theory and method ( $2^{\text {nd }}$ ed). New York: Open University Press. 